\title{
Formulation, characterization and evaluation of encapsulated bioherbicide on echinochloa cruss galli and phalaris minor
}

\author{
PARMEET SINGH* , RAVINDER KOHLI, LAL SINGH AND MANZOOR AHMAD GANIE
}

\begin{abstract}
Weeds management under organic agriculture demands organic herbicides/ bioherbicides. To address this issue an experiment was conducted in Centre of Environment Sciences and Technology, Central University of Punjab, Bathinda to study the effects of different concentration and bioassay of encapsulated essential oil extracted (EOs) from Callistemon viminalison Echinochloa cruss galli and Phalaris minor under lab conditions. Encapsulation efficiency of gum arabic and maltodextrin (GAMD) EOs increased from 26 to $31 \%$ for 4 to $8 \%$ of EOs concentration. The sizes of all the particles were found in the range of 1-10 $\mu \mathrm{m}$. The reduced size in case of EOs loaded GAMD-EOs encapsulates may be due to the application of spray drying method used during the preparation. Maximum germination inhibition was observed with P. minor as compared to the E. crus-galli L. The probable reason behind this may be the relatively smooth seed coat, smaller weight to volume ratio of P. minor as compared to the E. crus-galli L. Among all the treatments basal application of encapsulates with $8 \%$ essential oil was found more lethal and resulted in maximum phyto-toxicity by registering less shoot length and root length and fresh biomass weight. Also, the individual constituents of the EOs can be explored for their use as herbicides and then their encapsulated formulations can be used to scale up in the field conditions.
\end{abstract}

KEYWORDS

Essential Oils, Encapsulation, SEM, Weed Bioassay

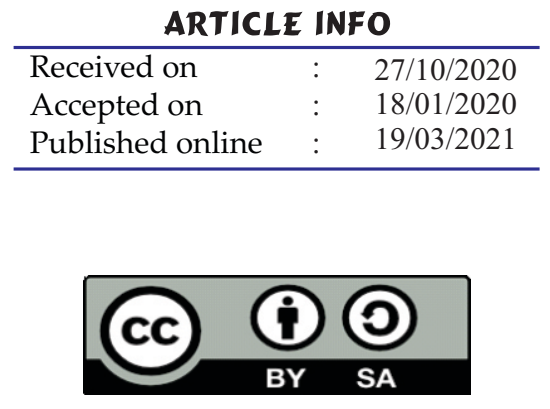

\section{INTRODUCTION}

W eeds (Plants growing at a place and at a time when they are not required) are strong impediment, cause substantial losses and even total crop failures, constitute a major component of rural poverty and threaten small-scale farmers' livelihood. Weeding is stressful and time consuming as the first weeded plot is re-infested again when the last one is weeded. The total economic losses of weeds will be much higher, if indirect effect of weeds on health, loss of biodiversity, nutrient depletion and grain quality is taken under consideration. Weeds compete with agricultural crops for all resources required for their growth and hence lead to economic losses (Gaba et al., 2014). The management of weeds by integrated way has been scientifically proved practice. Integrated weed management (IWM) involves a deliberate selection, integration and implementation of cost effective weed management strategies that best fit the farmers' resources, capabilities and farming systems. It further involves the use of monitoring and forecasting techniques, the introduction and enhancement of biocontrol agents, selective chemical and biopesticides, other non-chemical methods and implementation of area wise strategies. Although an overall comparison of different measures within the Integrated Weed Management toolbox demonstrates a performance advantage of chemical herbicide concerning criteria such as efficacy,

Sher-e-Kashmir University of Agriculture Sciences and Technology of Kashmir, Jammu \& Kashmir, India

*Corresponding author email : parmeetagron@gmail.com flexibility, time consumption and economics. But, there integration will reduce the problems and eventually facilitate sustainability of the ecosystem. To overcome the problem, research to find new molecules delivering novel properties, having new modes of action, effective in low concentration, environmentally safe, more target specific and economic is ongoing processes. Different researchers have made efforts to search new herbicide chemistry in various ways including natural products of animal and plant origin. Among the plant based natural products, Essential Oils (EOs) have been reported as suitable option for controlling weeds (Bouajaj et al., 2014; Ćavar et al., 2012; Sakee et al., 2011; Santos et al., 2015).Essential oil from the plant $C$. viminalis is rich in the 1,8 cineole (Eucalyptol), $\alpha$-pinine, + (-)-limonine, and $\alpha$-terpiniol. These are the volatile oil(s) constituted by a large number of strong aromatic components having distinctive odor, flavor or scent. These are the secondary metabolites of the plants and are present in their glandular hairs or secretory cavities of cell wall. These are present as droplets of fluid in the leaves, stems, bark, flowers, roots and/or fruits in different plants. Their extraction can be done by various methods like steam distillation, supercritical fluid extraction, extraction with subcritical $\mathrm{CO}_{2}$ and Cold pressing, etc. Although EOs has many beneficial properties yet their use is limited due to their properties which restrict their use or exploration in the development of herbicides, on large scale and natural conditions. Keeping above facts under consideration that Echinochloa cruss galli and Phalaris minor are economical weeds cereals crop in India 
(Singh et al.,2017), an experiment was conducted to study essential oil composition of callismiton viminalis leaves, formulation of biodegradable polymers and their bioherbicidal properties evaluation against two important test weeds.

\section{MATERIALS AND METHODS}

The study was carried out in Centre of Environment Sciences and Technology, Central University of Punjab, Bathinda. The climate is semiarid and the geographical location of the plant collection site (Experimental Site) is $75^{\circ} 00^{\prime}$ East longitude and $30^{\circ} 11^{\prime}$ North latitude with mean sea level $216 \mathrm{~m}$ amsl. For the essentials oils (EOs) extraction, the leaves of Callistemon viminalis were collected from the wild tree growing near the Central University of Punjab, Bathinda. Nearly 700g of freshly collected leaves were chopped into small pieces and mixed well with $2 \mathrm{~L}$ of water. The mixture was heated at $150^{\circ} \mathrm{C}$ for 2:30h using Clevenger's apparatus and distilled oil was collected from the nozzle of the condenser. The oil thus obtained was passed through sodium sulfate bed to remove water vapors, if any and stored at $4^{\circ} \mathrm{C}$ till further use. The composition and the identification of the EOs were studied using Gas Chromatograph coupled with Mass Spectrophotometer (Shimadzu QP 2010 Mass Spectrophot-ometer). Seeds of two monocots weeds namely E. crus-galli L. and P. minor were procured from the Department of Agronomy, Punjab Agriculture University, Ludhiana, Punjab. All the seeds of test plants were surface sterilized by dipping in $2 \%$ sodium hypochlorite for 1-2min followed by washing with distilled water and drying in sun light. The dried seeds were stored at room temperature $\left(25^{\circ} \mathrm{C}\right)$ for further studies. Seeds of all weeds were imbibed in distilled water for $12 \mathrm{~h}$ prior to lay germination trial.For the preparation of EOs loaded encapsulates, first the gum arabic and maltodextrin GAMD $(10 \%)$ were dissolved in distilled water and mixed in the $1: 1$ ratio.

Eos was dissolved in ethanol in concentration range $(4 \%$ \& $8 \%$ ) i.e. for $4 \% 1.2 \mathrm{ml}$ Eos and $1.8 \mathrm{ml}$ ethanol and $27 \mathrm{ml}$ of GAM Dlikewise for $8 \%$ we used $2.4 \mathrm{ml} \mathrm{EO}, 0.6 \mathrm{ml}$ ethanol and $27 \mathrm{ml}$ of GAMD. Dropwise mixing of EOs with polymers (GAMD) was carried under continuous stirring. After mixing the emulsions were homogenized (IKA T18ULTRATURRAX®Homozanizer) for $15 \mathrm{~min}$ on $3500 \mathrm{rpm}$ then kept on the stirring for $45 \mathrm{~min}$. The emulsion was used as the feed liquid for the spray-drying process. For each feed, approximately $100 \mathrm{ml}$ of emulsion was used. For the spray drying process, the Spray Mate II spray dryer (JISL Laboratory Equipment Mumbai) was used with nozzle size $0.7 \mathrm{~mm}$, operated at inlet temperature of $170^{\circ} \mathrm{C}$, out let temperature $85^{\circ} \mathrm{C}$, and $20 \mathrm{rpm}$ flow rate controlled using a peristaltic pump. After drying the emulsions, powder was stored at $4^{\circ} \mathrm{C}$ for further uses.SEM analysis of EOs encapsulates by Field Emission Scanning Electron Microscope (ZEISS Merlin Compact) to analyze surface structure. For the analysis, samples were mounted on a stainless steel stub using a double sticky carbon tape. Further encapsulation efficiency (\%EE) of the EOs encapsulates was determined using following equation given by Gomes et al.(2011).

Encapsulation Efficiency $=\frac{\text { Volume of loaded essential oils }}{\begin{array}{c}\text { Volume of Essential oil used in } \\ \text { encapsulated }\end{array}} \times 100$

For Bioassay studies, two types of set up were installed in which two weed namely Echinoloa cruss galli and Phalaris minor were experimental units. All the treatment combinations were replicated thrice and were carried out under lab conditions. Observations to be recorded were germination percentage, Seedling length and Biomass weightBoth the experiments were performed in a one way Completely Randomized Design with $0.05 \%$ probability. The post-hoc analysis was carried out by using Tukey Method in SAS software package.

\section{RESULTS AND DISCUSSION}

\section{Essential oil yield and composition}

The average yield of EOs was calculated $0.853 \pm 0.009 \%(w / w)$ from leaves of Callistemon viminalis. The result of compositional analysis is given in the Table 1.20 components were identified, in the essential oils by GC-MS. It is observed that the EOs from the plant C. viminalis was rich in the 1,8 -

Table 1: Composition of Essential oils of Callistemon viminalis

\begin{tabular}{l|lccc}
\hline RT & \multicolumn{1}{|c}{ Constituents } & KI & \% & $\begin{array}{c}\text { Chemical } \\
\text { class }\end{array}$ \\
\hline 6.83 & $\alpha$-Pinene & 1014 & 15.16 & $\mathrm{MH}$ \\
7.079 & $\alpha$-Thujene & 1020 & 0.69 & $\mathrm{MH}$ \\
10.065 & $\beta$-Pinene & 1098 & 3.75 & $\mathrm{MH}$ \\
12.77 & $\alpha$-Phellandrene & 1155 & 0.55 & $\mathrm{MH}$ \\
14.35 & (-)-Limonene & 1191 & 5.09 & $\mathrm{MH}$ \\
14.686 & Eucalyptol (1,8-cineol) & 1198 & 58.28 & $\mathrm{OM}$ \\
16.67 & $\gamma$-Terpinene & 1240 & 0.36 & $\mathrm{MH}$ \\
17.91 & o-Cymene & 1266 & 2.39 & $\mathrm{MH}$ \\
30.9 & $\beta$-Linalool & 1551 & 0.36 & $\mathrm{OM}$ \\
32.285 & 2-Norbornanol & 1583 & 0.26 & $\mathrm{OM}$ \\
32.521 & (-)-Terpinen-4-ol & 1588 & 0.26 & $\mathrm{OM}$ \\
33.015 & Caryophyllene & 1600 & 0.32 & $\mathrm{SH}$ \\
35.155 & L pinocarveol & 1653 & --- & $\mathrm{OM}$ \\
35.872 & UN* & 1662 & 0.74 & $\mathrm{OM}$ \\
36.8 & $\alpha$-Terpineol acetate & 1670 & -- & $\mathrm{OM}$ \\
36.935 & $\alpha$-Terpineol & 1697 & 7.19 & $\mathrm{OM}$ \\
42.749 & Germacrene D & 1749 & --- & $\mathrm{SH}$ \\
46.445 & UN & 1952 & --- & -- \\
47.04 & 1-dodecanol & 1969 & -- & $\mathrm{OM}$ \\
47.355 & Caryophyllene oxide & 1978 & 0.47 & $\mathrm{OS}$ \\
47.963 & 2-Propenoic acid, tridecyl ester & 1995 & 1.68 & $\mathrm{OS}$ \\
49.499 & Globulol & 2040 & --- & $\mathrm{OS}$ \\
50.918 & Epiglobulol & 2082 & --- & $\mathrm{OS}$ \\
55.64 & $\beta$-Eudesmol & 2229 & 0.249 & $\mathrm{OS}$ \\
56.99 & Aristolone & 2269 & 0.246 & $\mathrm{OS}$ \\
60.269 & cubenol & 2381 & -- & $\mathrm{OS}$ \\
60.871 & UN* & 2401 & -- & -- \\
64.823 & Humulane-1,6-dien-3-ol & 2539 & -- & $\mathrm{DH}$ \\
\hline Total identification & & 99.625 & \\
\hline & & & & \\
\hline & & &
\end{tabular}

MH: Monoterpenes Hydrocarbon, OM: Oxygenated monoterpenes SH: Sesquiterpenes Hydrocarbons OS: Sesquiterpenes Oxygenated DH: Diterpenes Hydrocarbon $\quad{ }^{*} \mathrm{UN}$ : unidentified 
cineole (Eucalyptol), $\alpha$-pinine, $+(-)$-limonine, and $\alpha$-terpiniol. The EOs synthesis in the aromatic plants is influenced by various factors like temperature, rainfall, humidity and morphology of plants (Figueiredo et al., 2008).

\section{Encapsulation efficiency}

In our study $65-70 \%$ of the EOs encapsulated powder were recovered with GAMD polymers. The product recovery in case of GAMD combination depends on the ratio of the polymer and EOs. In present study, the ratio of GA and MD was 1:1 and the EOs concentration was 4 and $8 \% \mathrm{w} / \mathrm{w}$. The reduction in the recovery were reported due loss of material during the emulsions prepration and drying (Ponce Cevallos et al., 2010). The encapsulation efficiency (EE) in present work increased with increase in the amount of EOsin the GAMD EOs encapsulates, the EE increased from 26 to $31 \%$ for 4 to $8 \%$ of EOs concentration.

Physico-chemical characterization of prepared encapsulates The prepared encapsulates were studied for following physical and chemical characteristics.

\section{Particle size analysis of Encapsulates}

Particle size analysis of GAMD-EOs encapsulates (Fig 2) was carried out to know the actual size range of the particles. The size of all the particles were found in the range of $1-10 \mu \mathrm{m}$. The reduced size in case of EOs loaded GAMD-EOs encapsulates may be due to the application of spray drying method used during the preparation. The spray drying process was able to

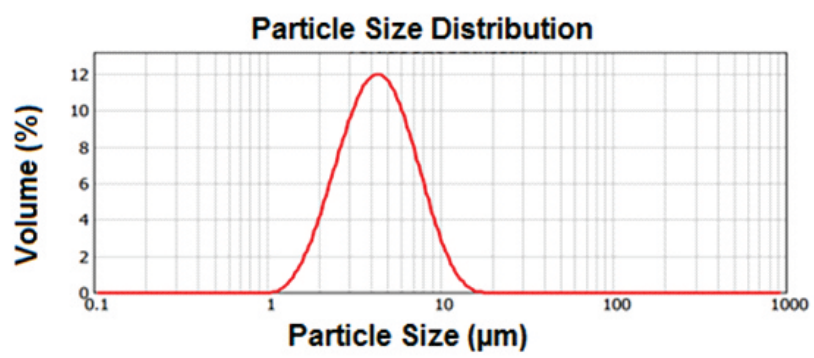

Fig 1: Particle size analysis of EOs Loaded GAMD encapsulates

provide more fine and reduced size to the GAMD-EOs encapsulates. Since the particles were in the micro meter size so they can also be termed as EOs microencapsulates.

Microscopic imaging by scanning electron microscopy (SEM) of EOs encapsulates

The particles of GAMD EOs encapsulates were observed
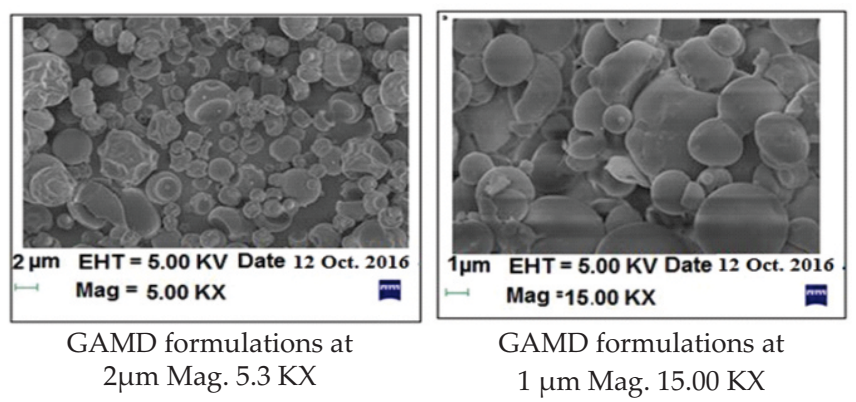

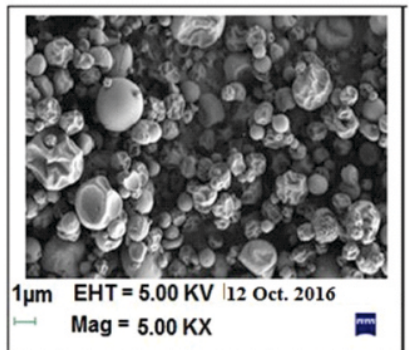

Essential oil loaded GAMD

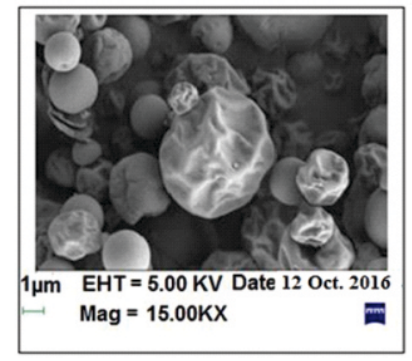

Essential oil loaded GAMD formulations at $2 \mu \mathrm{m}$ Mag. $5 \mathrm{KX}$ formulations at $1 \mu \mathrm{m}$ Mag. $15 \mathrm{KX}$ Fig 2: SEM analysis of GAMD and GAMD EO encapsulates at different magnifications

spherical in shape with smooth outer surface (Fig 2). The GAMD-EOs encapsulates were observed to have some cracks and shrink on the surface, which may be due to the release of EOs towards to outer surface of the particles. In addition to surface cracks, the EOs encapsulates also appeared bright as compared to the unloaded GAMD. This may be due to the presence of EOs on the surface of the loaded particles. The previous studies of flavors and aroma encapsulations in the gum arebic based polymeric systems reported similar pattern of surface morphology in microparticles (Alves et al., 2013). Further, the cracks and shirnks during encapsulation in the spray drying process were also supported by the previous studies of Fernandes et al.(2008).

\section{Effect on seed germination of weeds}

All the treatments have significant effect on seed germination (Table 2). There was insignificant change in percent seed germination on both the test weeds treated with EO and GAMD as compared to control. The percentage germination of these treatment is more than $90 \%$ in each case. The insignificant reduction in the per cent germination of both the weeds with essential oil without encapsulation indicates that essential oil gets volatilized and escapes out from the petri dish within a very short period of time. Also GAMD produced insignificant effect on both the weeds, indicating that GAMD did not have any phyto toxicity. On the other hand GAMD

Table 2: Effect of different treatments on seed germination of test weeds

\begin{tabular}{|c|c|c|c|}
\hline \multirow[b]{2}{*}{ Treatments } & \multicolumn{3}{|c|}{ Germination Percentage } \\
\hline & quantity & $\begin{array}{c}\text { Echinochloa } \\
\text { cross galli }\end{array}$ & $\begin{array}{l}\text { Phalaris } \\
\text { minor }\end{array}$ \\
\hline Absolute Control & & $98^{\mathrm{a}}$ & $96^{\mathrm{a}}$ \\
\hline Essential Oil & $20 \mathrm{ug} / \mathrm{cm}^{2}$ & 97 a & $94^{\text {a }}$ \\
\hline GAMD & $100 \mathrm{ug} / \mathrm{cm}^{2}$ & $98^{\mathrm{a}}$ & $96^{\mathrm{a}}$ \\
\hline $\begin{array}{l}\text { GAMD-Eo Encapsulate } \\
(4 \%) \text { as basal }\end{array}$ & $100 \mathrm{ug} / \mathrm{cm}^{2}$ & $63^{b}$ & $54^{\mathrm{b}}$ \\
\hline $\begin{array}{l}\text { GAMD-Eo Encapsulate } \\
(8 \%) \text { as basal }\end{array}$ & $100 \mathrm{ug} / \mathrm{cm}^{2}$ & $43^{c}$ & $40^{c}$ \\
\hline $\begin{array}{l}\text { GAMD-Eo Encapsulate } \\
(4 \%) \text { at } 4 \text { DAS }\end{array}$ & $100 \mathrm{ug} / \mathrm{cm}^{2}$ & 99 a & $96^{\mathrm{a}}$ \\
\hline $\begin{array}{l}\text { GAMD-Eo Encapsulate } \\
(8 \%) \text { at } 4 \text { DAS }\end{array}$ & $100 \mathrm{ug} / \mathrm{cm}^{2}$ & $97^{a}$ & $95^{\mathrm{a}}$ \\
\hline
\end{tabular}


encapsulates show significant reduction in seed germination. There is significant inhibition in seed germination when essential oil encapsulates are applied as basal application. It is more phyto toxic at $8 \%$ essential oil encapsulation. The encapsulates protect the essential oils from rapid degradation and their easy loss. The effect of essential oil encapsulates remain sustained due to slow and controlled release of Eos which was regulated by relaxation and bursting of polymers (Vishwakarma et al., 2016). Maximum germination inhibition was observed with P. minor as compared to the E. crus-galli L. The probable reason behind this may be the relatively smooth seed coat, smaller weight to volume ratio of $P$. minor as compared to the E. crus-galli L.

\section{Effect on Growth and weight of weeds}

All the encapsulated treatments were significantly superior in reducing the growth and weight of test weeds taken for study (Table 3). Basal dose at the time of sowing appear more lethal as compared to application at 4 DAS. This indicates the more sensitivity of germinating plumule and radicle to encapsulated essential oils. The Phalaris minor was found more susceptible to bioherbicides, but pattern of Phytotoxicity remains almost same. Among all the treatments basal application of encapsulates with $8 \%$ essential oil was found more lethal and result in maximum phyto-toxicity by registering less shoot length and root length and fresh biomass weight. Zunino and Zygadlo (2004) also reported that EOs constituent are responsible for the accumulation of lipid globules in the cytoplasm which induces reduction in mitochondria and blockage of DNA synthesis pathways.

Table 3: Effect of different treatments on shoot length, root length and fresh weight of test weeds

\begin{tabular}{|c|c|c|c|c|c|c|c|}
\hline \multirow[b]{2}{*}{ Treatments } & \multirow[b]{2}{*}{ quantity } & \multicolumn{3}{|c|}{ Echinochloa cruss galli } & \multicolumn{3}{|c|}{ Phalaris minor } \\
\hline & & $\begin{array}{l}\text { Shoot length } \\
(\mathrm{cm})\end{array}$ & $\begin{array}{l}\text { Root Length } \\
(\mathrm{cm})\end{array}$ & $\begin{array}{l}\text { Fresh } \\
\text { Weight } \\
\mu g\end{array}$ & $\begin{array}{l}\text { Shoot } \\
\text { length } \\
(\mathrm{cm})\end{array}$ & $\begin{array}{l}\text { Root } \\
\text { Length } \\
(\mathrm{Cm})\end{array}$ & $\begin{array}{l}\text { Fresh } \\
\text { Weight } \\
\mu \mathrm{g}\end{array}$ \\
\hline Absolute Control & -- & $4^{\mathrm{a}}$ & $3^{a}$ & $5^{a}$ & $3^{a}$ & $2.5^{\mathrm{a}}$ & $3^{a}$ \\
\hline Essential Oil & $20 \mu \mathrm{g} / \mathrm{cm} 2$ & $4^{\text {a }}$ & 3.2 a & $4.5^{a}$ & $2.8^{a}$ & $2.4^{\mathrm{a}}$ & $3^{a}$ \\
\hline GAMD & $100 \mu \mathrm{g} / \mathrm{cm} 2$ & $3.5^{\mathrm{a}}$ & $3.1^{\mathrm{a}}$ & $4.5^{\mathrm{a}}$ & $2.8^{\mathrm{a}}$ & $2.5^{\mathrm{a}}$ & $3.2^{\mathrm{a}}$ \\
\hline GAMD -Eo Encapsulate (4\%) as basal & $100 \mu \mathrm{g} / \mathrm{cm} 2$ & $2^{d}$ & $1.5^{\mathrm{d}}$ & $2.8^{\mathrm{d}}$ & $1.5^{\mathrm{d}}$ & $1.2^{\mathrm{d}}$ & $2.1^{d}$ \\
\hline GAMD -Eo Encapsulate (8\%) as basal & $100 \mu \mathrm{g} / \mathrm{cm} 2$ & $1.2 \mathrm{e}$ & $1.1 \mathrm{e}$ & $1.4 \mathrm{e}$ & $1.2^{\mathrm{e}}$ & $1.0^{\mathrm{e}}$ & $1.2 \mathrm{e}$ \\
\hline GAMD -Eo Encapsulate (4\%) at 4 DAS & $100 \mu \mathrm{g} / \mathrm{cm} 2$ & $2.5^{c}$ & $1.8^{c}$ & $3.1^{c}$ & $2.0^{c}$ & $1.5^{c}$ & $2.5^{c}$ \\
\hline GAMD -Eo Encapsulate (8\%) at 4 DAS & $100 \mu \mathrm{g} / \mathrm{cm} 2$ & $2.2^{\mathrm{c}}$ & $1.6^{c}$ & $3.2^{\mathrm{c}}$ & $2.9^{c}$ & $1.8^{\mathrm{c}}$ & $2.2^{c}$ \\
\hline
\end{tabular}

\section{CONCLUSION}

Present study which explored Bioherbicide formulation is an important component of Organic farming. On the basis of findings, it can be concluded that the EOs of $C$. viminalis has the potent herbicidal properties which can alter the physiological and biochemical process of the weeds. The encapsulation process enhances the stability of EOs and facilitates its applicability as phototoxic ingredient for the inhibition of weeds. In the future, the number of weeds with allelopathic properties should be exploited for making bioherbicides in the form of encapsulates. These bioherbicides

\section{REFERENCES}

Alves SF, Borges LL, Santos TO, De Paula JR, Conceição EC and Bara MTF. 2013. Microencapsulation of Essential Oil from Fruits of Pterodon emarginatus Using Gum Arabic and Maltodextrin as Wall Materials: Composition and Stability. Drying Technology 32: 96-105.

Bouajaj S, Romane A, Benyamna A, Amri I, Hanana M, Hamrouni L and Romdhane M. 2014. Essential oil composition, phytotoxic and antifungal activities of Ruta chalepensis L. leaves from High Atlas Mountains (Morocco). Natural Product Research 28: 1910-1914.

Cavar S, Maksimoviš M, Idic D and Pariš A. 2012. Chemical composition and antioxidant and antimicrobial activity of essential oil of Artemisia annua L. from Bosnia. Industrial Crops should be integrated with synthetic herbicides to reduce herbicidal load on the ecosystem. Also, the individual constituents of the EOs can be explored for their use as herbicides and then their encapsulated formulations can be used for scale up in the field conditions.

\section{ACKNOWLEDGMENT}

The author acknowledges the support of Indian National Science Academy by INSA fellowship for funding to conduct this study.

and Products 37: 479-485.

Fernandes LP, Oliveira WP, Sztatisz J and Novak C. 2008. Thermal properties and release of Lippia sidoides essential oil from gum arabic/maltodextrin microparticles. Journal of Thermal Analysis and Calorimetry 94: 461-467.

Figueiredo AC, Barroso JG, Pedro LG and Scheffer JJC. 2008. Factors affecting secondary metabolite production in plants: volatile components and essential oils. Flavour Fragrance. Journal 23: 213-226.

Gaba S, Fried G, Kazakou E, Chauvel B and Navas ML. 2014. Agroecological weed control using a functional approach: a review of cropping systems diversity. Agronomy for Sustainable Development 34: 103-119.

Ponce Cevallos PA, Buera MP and Elizalde BE. 2010. Encapsulation of 
cinnamon and thyme EOs components (cinnamaldehyde and thymol) in $\beta$-cyclodextrin: Effect of interactions with water on complex stability. Journal of Food Engineering 99: 70-75.

Sakee U, Maneerat S, Cushnie TT and De-Eknamkul W. 2011. Antimicrobial activity of Blumea balsamifera (Lin.) DC. extracts and essential oil. Natural Product Research 25: 1849-1856.

Santos EH, Kamimura JA, Hill LE and Gomes CL. 2015. Characterization of carvacrol $\beta$-cyclodextrin inclusion complexes as delivery systems for antibacterial and antioxidant applications. LWT-Food Science and Technology 60: 583-592.

Singh AK, Singh AK, Kumar R, Prakash V, Sundaram PK and Yadav SK. 2017. Indian Cereals Saga: Standpoint and Way Forward.
Journal of AgriSearch 4 (1): 1-10.

Vishwakarma GS, Gautam N, Babu JN, Mittal S and Jaitak V. 2016. Polymeric Encapsulates of Essential Oils and their Constituents: A Review of Preparation Techniques, Characterization and Sustainable Release Mechanisms. Polymer Reviews Doi: 10.1080/15583724.2015.1123725.

Vishwakarma GS, Sharma S and Mittal S. 2015. Phytotoxic selectivity analysis of Eucalyptus tereticornis essential oil against rice, Oryza sativa and its weeds, Echinochloa crus-galli and Cyperus rotundus. International Journal of Farm Sciences 5: 78-90.

Zunino MP and Zygadlo JA. 2004. Effect of monoterpenes on lipid oxidation in maize. Planta 219: 303-309.

\section{Citation:}

Singh P, Kohli R, Singh L, Ganie MA. 2021. Formulation, characterization and evaluation of encapsulated bioherbicide on Echinochloa cruss galli and Phalaris minor. Journal of AgriSearch 8 (1): 50-54 